\title{
PERCEPÇÃO, SATISFAÇÃO E DECISÕES DE PROJETO NO MUSEU DO FUTEBOL
}

CACCIATORI, Melissa M. F.

Faculdade de Arquitetura e Urbanismo da USP, melissa.cacciatori@usp.br

FELIX, Patricia M. A. C.

Faculdade de Arquitetura e Urbanismo da USP, patricia.macf@usp.br

GARCIA, Mariana F. M.

Faculdade de Arquitetura e Urbanismo da USP, mariana.fferreira@gmail.com

MIRANDA, Regina C. A. N.

Escritório Teixeira Miranda Arquitetura, regina@teixeiramiranda.com.br

MORAIS, Renata D. B.

Faculdade Estácio de Carapicuíba, redborges@gmail.com

ORNSTEIN, Sheila W.

Faculdade de Arquitetura e Urbanismo da USP, sheilawo@usp.br

\section{RESUMO}

A gestão exigida na área de projetos demanda especialistas em vários temas. A importância do profissional integrador é imperiosa e encontra respaldo nos procedimentos metodológicos BIM (Building Information Modeling), a fim de hierarquizar demandas e integrar questões de qualidade do ambiente construído, do projeto ao uso, manutenção e desmontagem. Como estudo de caso, o Museu do Futebol (MF), com sua exposição interativa, que busca ampliar a geração de memórias do visitante através de estímulos sensoriais, abrange diversas demandas, de acordo com o perfil de usuário (visitantes e colaboradores). Resultante de um estudo de caráter exploratório, desenvolvido no âmbito de uma disciplina de Pós-graduação, este artigo objetiva expor a abordagem multi-métodos da Avaliação Pós-Ocupação (APO) aplicada ao MF. Destaca-se o percurso metodológico abrangendo itens de conforto ambiental e segurança no uso, e os resultados obtidos através de procedimentos que geraram diagnósticos e diretrizes de projeto, podendo retroalimentar um futuro projeto de renovação de exposição permanente do MF.

Palavras-chave: Museu Interativo, Percepção e Satisfação do usuário, Tomadas de Decisão, Projeto Integrado.

\begin{abstract}
The management required in the design field demands specialists in diverse fields. The importance of an integrating professional is imperative and finds support in BIM (Building Information Modeling) procedures, in order to hierarchize demands and integrate quality issues regarding the built environment, from design to use, maintenance and disassembly. As a case study, the Football Museum (FM), with its interactive exhibition that seeks to extend the generation of visitor memories through sensorial stimuli, encompasses several demands, according to the user profile (visitors and staff). Result of an exploratory study, developed in the scope of a Graduate discipline, this article aims to expose the multi-method approach of the Post-Occupancy Evaluation (POE) applied to the FM. It stands out the applied methodology in items of environmental comfort and safety in use, and the results obtained through these procedures, that generated diagnoses and related design guidelines to feedback design data that may support the FM's permanent exposure renewal project.
\end{abstract}

Keywords: Interactive Museum, Users Perception and Satisfaction, Decision Making, Integrated Project.

CACCIATORI, M. M. F.; FELIX, P. M. A. C.; GARCIA, M. F. M.; MIRANDA, R. C. A. N.; MORAIS, R. D. B.; ORNSTEIN, S. W. Percepção, Satisfação e Decisões de Projeto no Museu do Futebol. In: SIMPÓsIO BRASILEIRO DE QUALIDADE DO PROJETO NO AMBIENTE CONSTRUÍDO, 6., 2019, Uberlândia. Anais... Uberlândia: PPGAU/FAUeD/UFU, 2019. p. 198-212. DOl https://doi.org/10.14393/sbqp19020. 


\section{INTRODUÇÃO}

A implementação da metodologia e das ferramentas BIM, representa uma mudança de paradigma para a prática de projetos em Arquitetura e Engenharia, demandando um perfil profissional integrador aos intervenientes das várias etapas de projeto, implantação, uso e desmontagem de uma edificação (AIA, 2007). Habilidades de coordenação interdisciplinar (ALHARBI, EMMITT, \& DEMIAN, 2015), de gestão em alto nível e no nível das especialidades, devem estar presentes neste perfil. Paralelamente, o bemestar dos usuários de edifícios se apresenta como um novo objetivo hierarquizante, sob o qual estudiosos, pesquisadores e nichos tecnológicos buscam ordenar as demandas do ambiente construído, do planejamento ao uso (IWBL, 2018).

Neste cenário da prática de projeto e gestão integrados, será apresentado o caso de um estudo no âmbito da APO, realizado em caráter exploratório no Museu do Futebol (MF), que constitui o trabalho de referência deste artigo (CACCIATORI, et al., 2018). Este estudo foi realizado em 2018, para a disciplina Avaliação Pós-Ocupação (APO) do Ambiente Construído, do Programa de Pós-Graduação da Faculdade de Arquitetura e Urbanismo da Universidade de São Paulo (FAU-USP).

O MF (Figura 1) apresenta uma exposição interativa e uma arquitetura adaptada, implantada no eixo Leste-Oeste (Erro! Fonte de referência não encontrada.Figura 2) distribuída em quatro pavimentos (Figura 3), localizados embaixo das arquibancadas do Estádio Municipal Paulo Machado de Carvalho, mais conhecido como Estádio do Pacaembu, na cidade de São Paulo. Esta adaptação restringiu muitas decisões de projeto e da exposição, além de ter se tratado de intervenção em edificação patrimoniada. A exposição permanente adotou recursos tecnológicos audiovisuais e variações de condições de iluminação, temperatura e acústicas para provocar sensações e emoções em seus visitantes, transportando-os para o mundo do futebol.

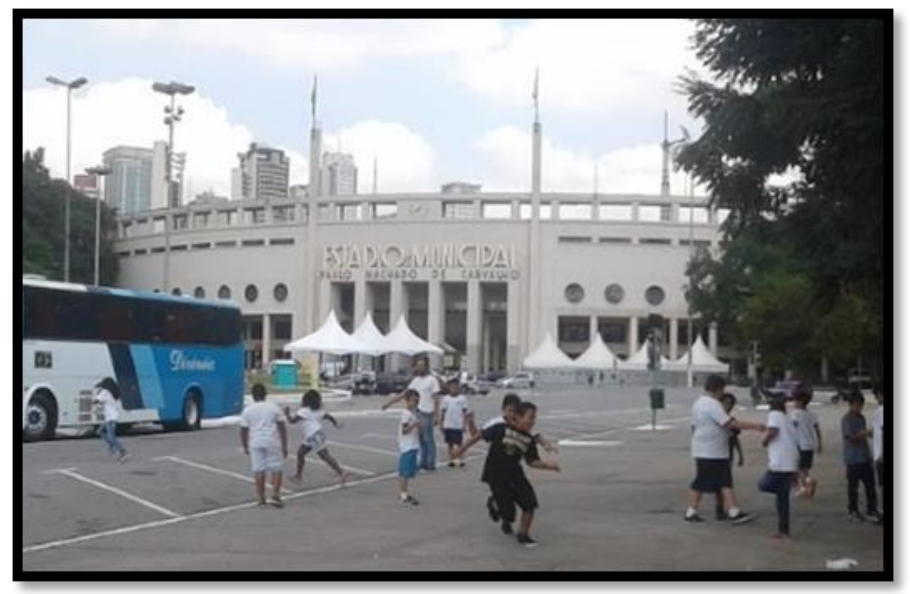

Figura 1 - Vista da Fachada Norte do Estádio Paulo Machado de Carvalho - Pacaembu.

Fonte: (CACCIATORI, et al., 2018) 


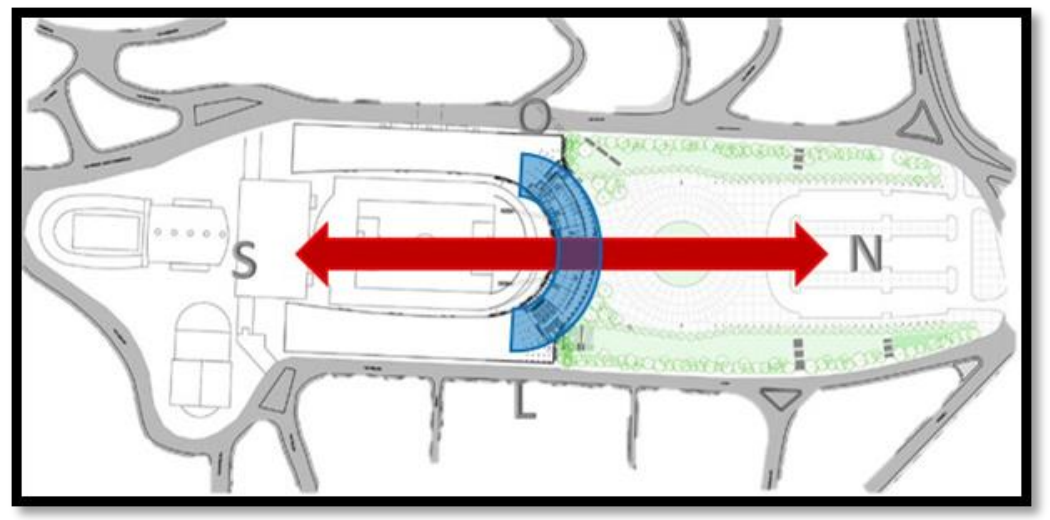

Figura 2 - Eixo de implantação do MF no sentido Leste-Oeste. Fonte: (CACCIATORI, et al., 2018)

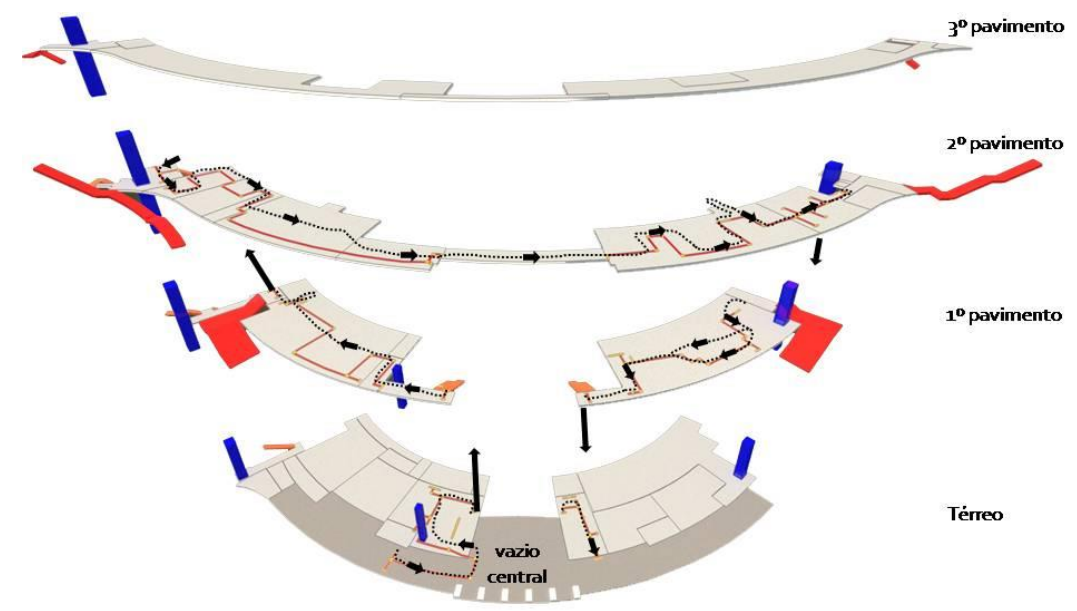

Figura 3 - Pavimentos e Fluxos do MF. Fonte: (CACCIATORI, et al., 2018)

Museus com propostas interativas se estabelecem, quer seja pela ação do próprio visitante que interage de formas inesperadas com o ambiente, como no Georges Pompidou - Renzo Piano (1977) (PUGLIESI, 2018) e no Museu du quai Branly do arquiteto Jean Nouvel, ou pela ação deliberada do arquiteto de promover interação através da ampliação dos estímulos sensoriais, adotando ou não recursos tecnológicos, como o Museu do Quatar, também de Jean Nouvel, nos Museus Catavento e do Futebol, ambos em São Paulo, e no Museu do Amanhã no Rio de Janeiro.

O objetivo deste artigo é evidenciar a necessidade de uma abordagem integrada, especialmente quando as demandas de usuários, sistemas e partidos da exposição podem ser concorrentes, como as demandas de conforto ambiental (GONÇALVES, 2016) e de segurança. Nessa APO, no processo de sistematização dos dados coletados e no possível impacto destas informações, decorrentes da APO, na constituição e na operação do museu, destacaram-se os processos decisórios que constantemente precisam hierarquizar demandas, respondendo a cada etapa, para quem se projeta um museu interativo'.

${ }^{1}$ No âmbito deste trabalho, o museu interativo é caracterizado por promover experiências sensoriais diversas em seus visitantes, além da contemplação de objetos e artefatos. 


\section{FUNDAMENTAÇÃO TEÓRICA}

A busca pela interação entre acervo, ambiente construído e público, presente nos projetos de museus contemporâneos, segundo Veiga e Andery (2014) representa uma mudança de significado de espaços museográficos. O projeto demanda uma dinâmica de briefing mais complexa, que não se encerra na etapa de concepção (ANDERY e VEIGA, 2013), e uma intensa colaboração entre os múltiplos agentes, para o alinhamento de requisitos e valores.

Estes mesmos autores apontam a necessidade de uma abordagem integrada, que pode se valer da adoção de termos de referência para elaboração de projetos complexos e softwares, tais como plataformas BIM. Destacam-se dois pontos de encontro específicos entre as considerações dos autores acima e os resultados observados no trabalho de referência deste artigo:

- Que a interação entre acervos interativos e ambiente construído, cria novas formas de percepção. O presente trabalho evidencia que estas percepções devem ser identificadas e sistematizadas na forma de dados que possam direcionar projetos similares ou retroalimentar projetos de reformas e renovações;

- Que são admitidos outros mecanismos de colaboração entre curadoria, profissionais especialistas e projetistas, além de softwares e plataformas BIM. Neste artigo aponta-se a APO como um destes mecanismos de apoio a decisão e integração, através de seus processos de coleta e sistematização da informação.

Embora a APO não seja um processo novo, a adoção da mesma em projetos ainda é recebida pelas equipes de projeto e demais intervenientes como novidade. Um esforço de acomodação para o uso de seus resultados no projeto é requerido. No contexto atual, os agentes de projeto estão em fase de acomodação e incorporação, tanto quanto a adoção da APO quanto das abordagens de projeto integrado.

Ao propor bases conceituais e teóricas para o design digital Oxman (2006) analisou o histórico de teorias de design - o projeto baseado no papel, que antecederam àquele momento, e assumiu o pressuposto de que o design digital -intermediado por ferramentas computacionais, representa uma nova forma de se projetar e não apenas a continuidade do modelo anterior em uma nova mídia. Três são os destaques do trabalho de Oxman no âmbito do presente artigo:

a) Que a elaboração de projetos em meio digital (digital design thinking) constitui uma nova abordagem de projeto, que explora novas formas de relação entre o projetista, a imagem e a informação;

b) Que uma nova geração de especialistas em design digital surge na medida em que as mídias digitais se tornam mais complexas, exigindo mais conhecimento de softwares e linguagens, manipulação e manutenção de modelos complexos e sistemas paramétricos, por exemplo;

c) São propostas 5 classes de modelos que constituem referenciais paradigmáticos para o mapeamento de processos e estruturas da abordagem de modelos digitais, dentre eles, o modelo de "performance", que se configura como um processo de geração da "forma" a partir de simulações de desempenho ou comportamento do objeto. 
A complexidade do projeto de museus interativos, demanda uma abordagem integrada que define as novas relações entre projetista, imagem e a informação (a) traduzidas também pelo termo BIM, no contexto apresentado por Succar (2009), no qual o "modelo" significa "imagem". Uma proposta de interação baseada na exploração de sensações promovidas por estímulos ambientais requer, além especialistas em design digital (b) familiarizados com a metodologia BIM, especialistas em disciplinas de conforto ambiental, habilitados a implementar o modelo de "performance" (c).

Succar (2009) apresenta três campos de atividade, que interagem e se sobrepõem no processo de implementação da metodologia BIM: Tecnologia, Processo e Regulamentos e, cada um, com dois subcampos: agentes e entregáveis (Figura 4).

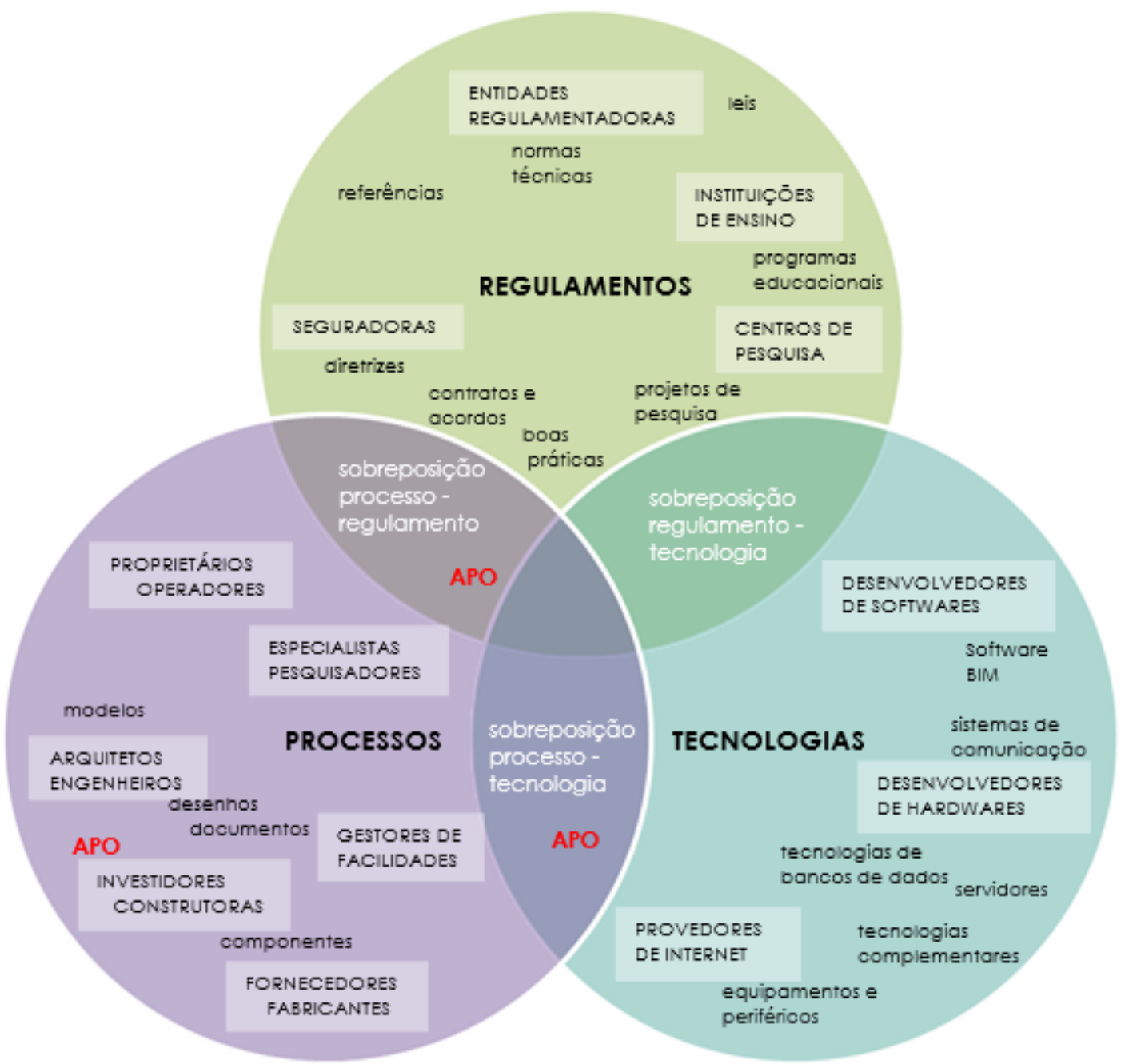

Figura 4 - Diagrama de Venn - Sobreposições de Campos de Atividade do Projeto Integrado, Agentes e Entregáveis e a localização da APO

Fonte: Adaptado pelas autoras de Succar (2009)

A APO configura-se como um Processo de gestão da qualidade de projeto e de manutenção e operação (ORNSTEIN, ANDRADE e LEITE, 2005), e seus resultados podem ser entradas para os campos de Tecnologia e de Regulamentos. Isto porque, dado o dinamismo e exclusividade das premissas de cada empreendimento, nem sempre se encontram disponíveis padrões normativos ou ferramentas específicas.

Segundo Bordass e Leaman (2005), o processo da APO busca responder: 
- Como este edifício está funcionando?

- O funcionamento atual corresponde às intenções de projeto?

- Este edifício pode ser melhorado?

- Como os edifícios futuros desta tipologia podem ser melhorados?

O acesso às respostas destas questões aumenta o potencial de agregar valor ao edifício e contribuir para melhorar as condições de uso, incluindo benefícios na qualidade de vida e saúde de visitantes e usuários permanentes, no caso de projetos e renovações de museus.

\section{MÉTODOS}

A abordagem multi-métodos da APO, possibilita O mapeamento da Percepção e da Satisfação de usuários Vs. Desempenho Físicos Vs. Decisões de Arquitetura, gerando importantes informações de feedback para novos projetos (BORDASS \& LEAMAN, 2005). O processo de APO do MF foi dividido entre dois eixos, avaliando desempenho físico e percepção de condições de seis temas:

I. Museografia: Conforto Térmico, Lumínico, Acústico e Acessibilidade;

II. Manutenção: Segurança e Proteção contra Incêndio e Segurança durante o Uso.

A Figura 5 abaixo, sintetiza processos de avaliação, instrumentos e resultados do estudo.

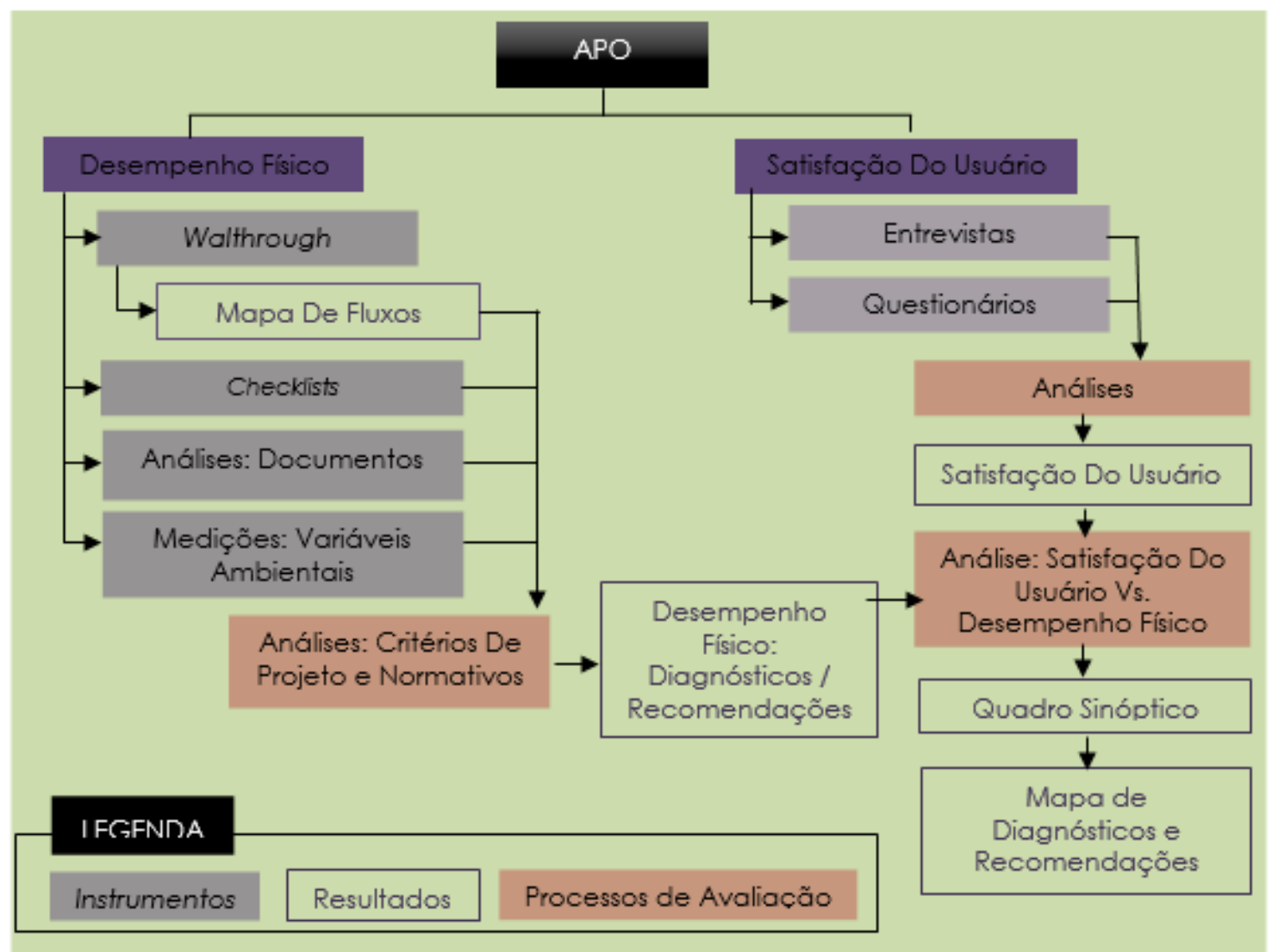

Figura 5 - Fluxograma de Processo - APO do Museu do Futebol

Fonte: (CACCIATORI, et al., 2018) 
Os temas abordados foram definidos a partir de suas relações e subordinação aos eixos temáticos, e do seu potencial de influenciar a experiência de usuários no contexto do museu interativo.

Para avaliação do desempenho físico dos temas do eixo de Museografia, foram realizadas inspeções visuais a partir do percurso (walkthrough), mapeamento de fluxos e medições de variáveis ambientais ao longo do percurso mapeado - método transecto ${ }^{2}$. Este método foi determinado por questões de viabilidade, dadas as limitações de tempo e recursos do estudo, além de sua adequação, por se tratar de tempos curtos de medição (10 minutos em cada ponto), compatíveis com o tempo de permanência dos visitantes em cada ponto mapeado (Figura 6).

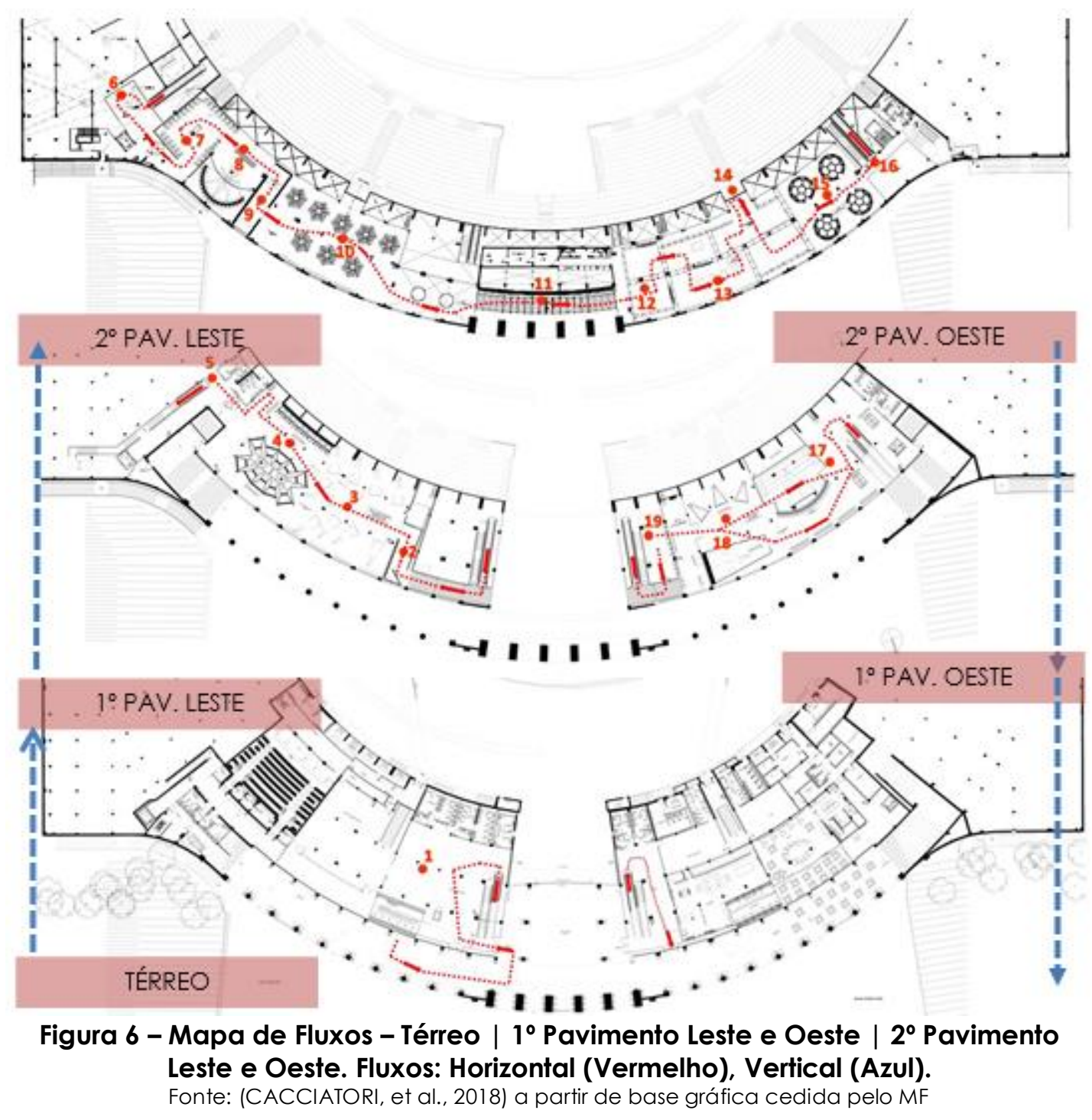

As medições de condições ambientais realizadas foram:

- Temperatura e Velocidade do Ar;

- Temperatura radiante das superfícies (Figura 7);

${ }^{2}$ Método adotado em avaliações urbanas e em campo aberto e é definido como método do transecto. Os objetivos do estudo e disponibilidade de tempo são fatores determinantes do comprimento, do percurso e das distâncias entre os pontos. (KREBS, 1989 apud ARAU JO, et al., 2010). 
- Iluminância, Luminância das superfícies (Figura 8);

- Níveis Sonoros.
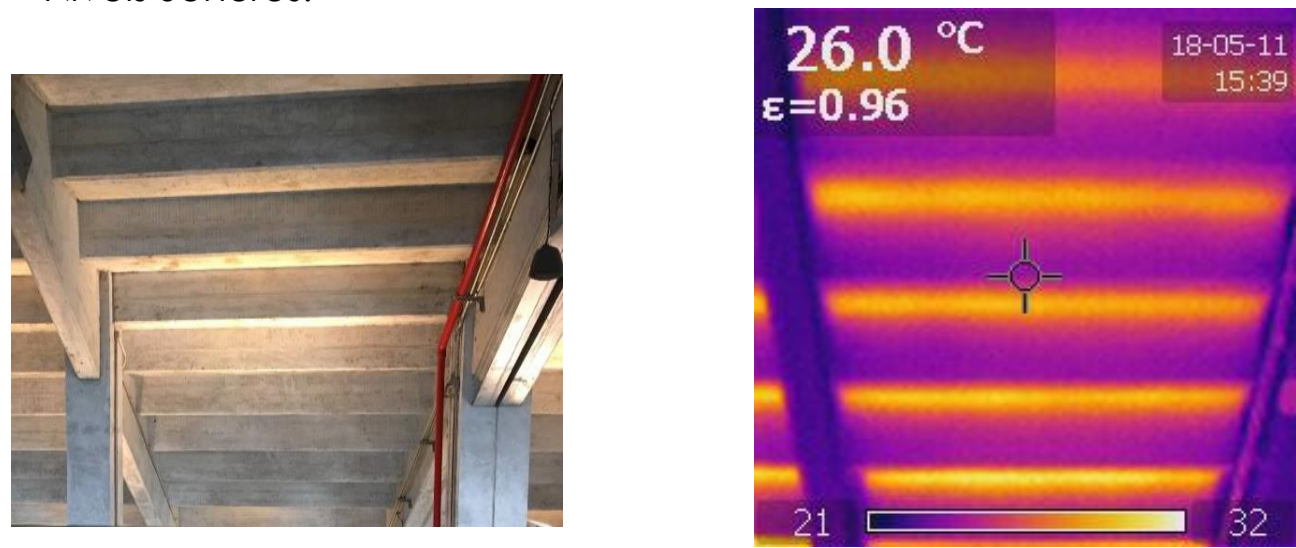

Figura 7 - Foto termográfica da arquibancada - vista da Passarela Boas vindas do Pelé. Data: 11.05.18. Temperatura interna: $25,4^{\circ} \mathrm{C}$. Temperatura externa - $15 \mathrm{~h}: 27^{\circ} \mathrm{C}$ (INMET, 2018)

Fonte: (CACCIATORI, et al., 2018)
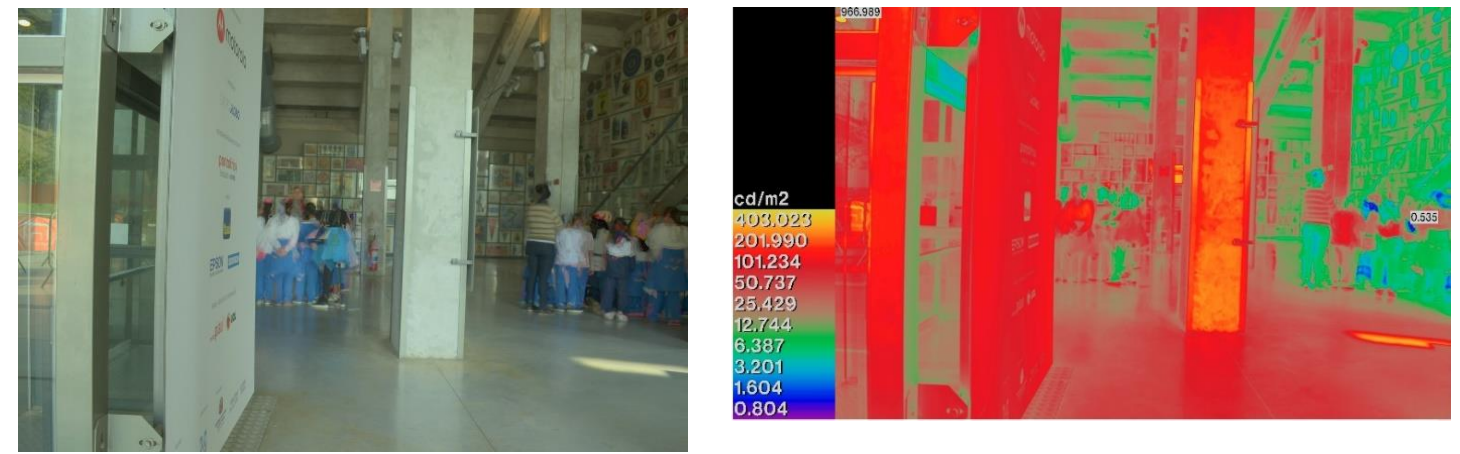

Figura 8 - Medições de luminância através de fotos HDR 3 (High Dynamic Range) (esquerda) e suas respectivas imagens de cores falsas (direita) Fonte: (CACCIATORI, et al., 2018)

No eixo de Manutenção, foram realizadas inspeções visuais ao longo do percurso mapeado (walkthrough), análise de documentos, checklists e testes normatizados. Para avaliação dos Sistemas de Proteção e Segurança contra incêndio (Quadro 1), foi aplicado um dos checklists elaborados para o estudo de caso, em pontos de ocorrência, mapeados ao longo dos 4 pavimentos do museu, exemplificado na Figura 9. Para Segurança durante o Uso e Conforto tátil e antropodinâmico, também foram mapeados pontos observados no percurso, e aplicados checklists e testes normatizados, como demonstrado na Figura 10.

\footnotetext{
3 A técnica HDR "High Dynamic Range", ou "Grande Alcance Dinâmico", busca representar melhor áreas mais escuras e mais claras, criando vários pontos de ajuste em uma única fotografia.
} 
Quadro 1 - Legenda dos Sistemas de Proteção e Segurança Contra Incêndio

\begin{tabular}{|c|l|}
\hline PONTOS & \multicolumn{1}{|c|}{ SISTEMAS } \\
\hline 1 & SP 01 - Sistemas de detecção e alarme de incêndio \\
\hline 2 & SP02 -Sistemas de extintores \\
\hline 3 & SP03-Sistemas de hidrantes e de mangotinhos para \\
\hline 4 & SP04 -Sistemas de chuveiros automáticos "sprinklers" \\
\hline 5 & SP 05-Segurança estrutural contra incêndio \\
\hline & SP -Controle de materiais de acabamento \\
\hline 6 & SP06-Rotas de de Fuga-Saídas de emergência \\
\hline 7 & SP07 -Saídas de emergência \\
\hline 8 & SP08-Sistema de iluminação de emergência \\
\hline 9 & SP09 -Sinalização de emergência \\
\hline 10 & SP10- Acesso as viaturas do CB \\
\hline
\end{tabular}

Fonte: (CACCIATORI, et al., 2018)

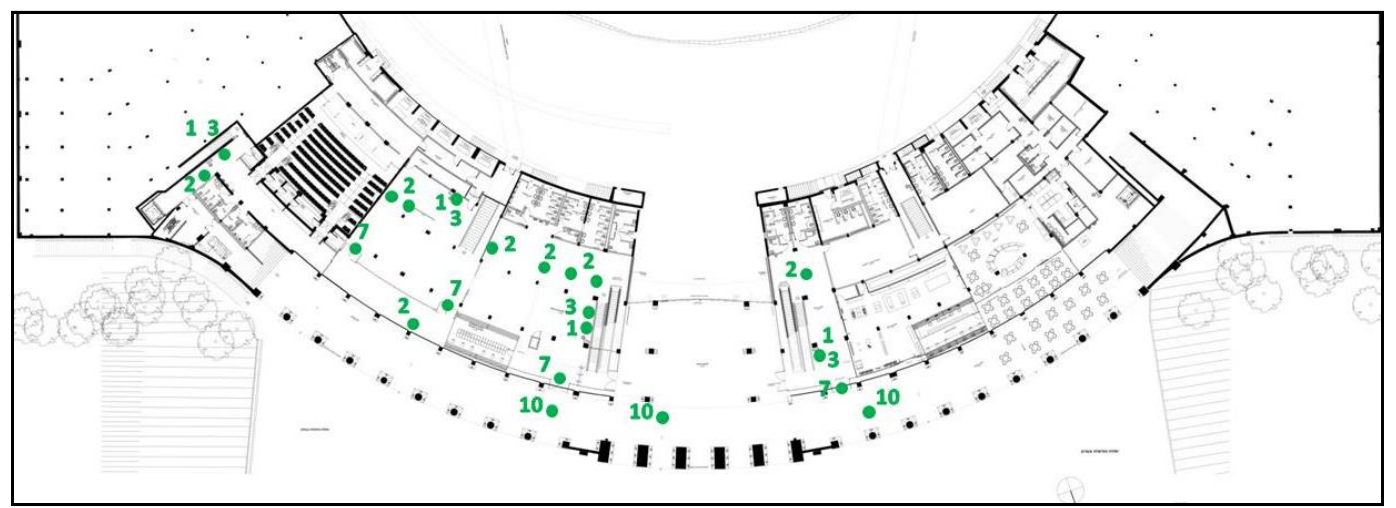

Figura 9 - Planta Pavimento Térreo - Pontos de aplicação: checklist de segurança e proteção contra incêndio

Fonte: (CACCIATORI, et al., 2018) a partir de base gráfica cedida pelo MF

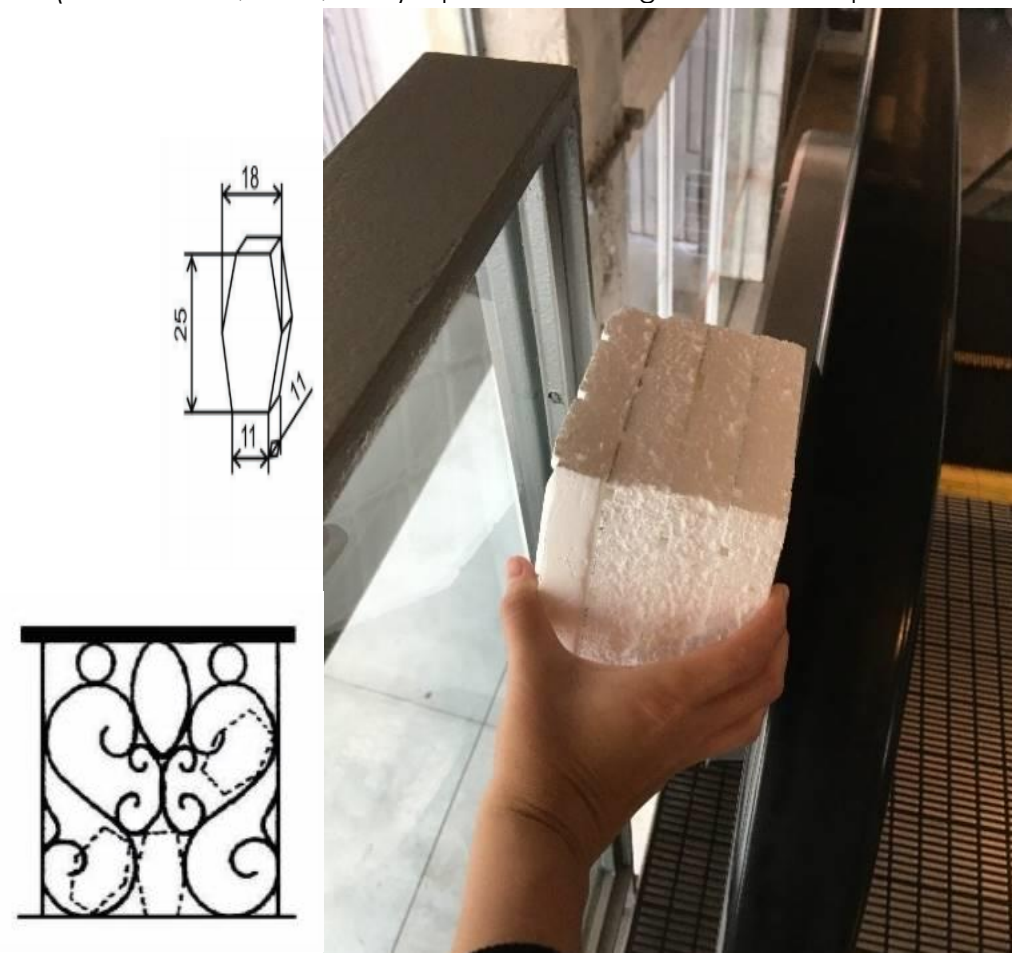

Figura 10 - Gabarito prismático de $25 \times 11 \times 11 \mathrm{~cm}$ e folgas entre perfis (esquerda). Teste de passagem do gabarito prismático em guarda-corpo (direita)

Fonte: NBR 14.718 - Guarda-corpos em edifícios (ABNT, 2008) (direita) (CACCIATORI, et al., 2018) (esquerda)

A Percepção e a Satisfação de Usuários foram avaliadas a partir de:

- Entrevistas com 4 pessoas chaves; 
- Questionários aplicados à uma amostra de 273 visitantes, calculada com margem de erro de $5 \%$ e nível de confiança de $95 \%$ a partir de uma população média de 14.300 visitantes mensais, maiores de 18 anos;

- Questionários aplicados junto à 22 funcionários do museu.

\section{RESULTADOS E DISCUSSÃO}

Além da elaboração dos dois grandes produtos, que sintetizam o estudo - o quadro sinóptico, com diagnósticos e recomendações resultantes, e o mapa, localizando cada quesito avaliado, relacionado aos diagnósticos e às recomendações, destacam-se dois produtos do processo de aplicação da APO no MF:

1. A verificação de aplicabilidade de normas técnicas aos 5 temas, classificando-as em relação ao estudo, como aplicáveis (verde), parcial ou potencialmente aplicáveis (amarelo) ou não aplicáveis (vermelho), e seleção de critérios para a avaliação do Museu do Futebol. O Quadro 2 apresenta as normas verificadas para os temas de conforto ambiental, como exemplo;

2. A produção de 11 quadros resumo contemplando diagnósticos e recomendações, separados por tema, conforme exemplificado no Quadro 3. Ao fim, constituem-se importantes ferramentas para o projeto integrado, com informação resumida, suficiente para processos de gestão e mais detalhada, para o nível da especialidade.

\section{Quadro 2 - Verificação de aplicabilidade de normas técnicas ao estudo e} Critérios de Avaliação definidos - temas de Conforto Ambiental

\begin{tabular}{|c|c|c|}
\hline $\begin{array}{c}\text { Normas Revisadas e outras Referências Adotadas / } \\
\text { Classificação no estudo }\end{array}$ & $\begin{array}{l}\text { Tema - Área } \\
\text { de Conforto } \\
\text { Ambiental }\end{array}$ & Critérios definidos \\
\hline $\begin{array}{l}\text { ABNT NBR 15220:2005 - Desempenho } \\
\text { térmico de edificações }\end{array}$ & TÉRMICA & NA* \\
\hline $\begin{array}{lcr}\text { ABNT NBR } 15575: 2013 & - & \text { Edificações } \\
\text { habitacionais } & - & \text { Desempenho } \\
\text { (NBR 15575:2013) } & & \\
\end{array}$ & TÉRMICA & NA* \\
\hline $\begin{array}{l}\text { ANSI/ASHRAE } \quad \text { Standard } 55-2017 \quad-\text { - } \\
\text { Condições Térmicas Ambientais } \\
\text { Ocupação Humana }\end{array}$ & TÉRMICA & NA* \\
\hline $\begin{array}{l}\text { ANSI/ASHRAE Standard 62.1-2016 - } \\
\text { Ventilação para qualidade do Ar Aceitável }\end{array}$ & TÉRMICA & NA* \\
\hline $\begin{array}{l}\text { Norma Regulamentadora do Ministério do } \\
\text { Trabalho - NR } 15 \text { - ATIVIDADES E OPERAÇÕES } \\
\text { INSALUBRES, } 1990 \text { (NR-15) }\end{array}$ & TÉRMICA & NA* \\
\hline $\begin{array}{l}\text { Norma Regulamentadora do Ministério do } \\
\text { Trabalho - NR } 17 \text {-ERGONOMIA, } 1990 \text { (NR-17) }\end{array}$ & TÉRMICA & NA* \\
\hline $\begin{array}{l}\text { ANSI/ASHRAE/IES Standard 90.1-2016 - } \\
\text { Energy Standard for Buildings Except Low- } \\
\text { Rise Residential Buildings }\end{array}$ & TÉRMICA & NA* \\
\hline $\begin{array}{l}\text { ABNT NBR 16401-2:2008 - Instalações de ar- } \\
\text { condicionado - Sistemas centrais e unitários } \\
\text { (Parte 2: Parâmetros de conforto térmico) }\end{array}$ & TÉRMICA & $\begin{array}{l}\text { Temperatura Operativa: } \\
21^{\circ} \mathrm{C}-23.5^{\circ} \mathrm{C} \text { e Umidade } \\
\text { Relativa [\%]: } 60 \%\end{array}$ \\
\hline ABNT NBR 15215-1: 2005 - Iluminação Natural & ILUMINAÇÃO & $\mathrm{NA}^{*}$ \\
\hline
\end{tabular}




\begin{tabular}{|c|c|c|}
\hline $\begin{array}{l}\text { Instrução técnica - IT N0.18/2012 - } \\
\text { lluminação de emergência }\end{array}$ & $\begin{array}{l}\text { SEGURANÇA + } \\
\text { ILUMINAÇÃO }\end{array}$ & Nível Segurança: 3 lux \\
\hline $\begin{array}{l}\text { ABNT NBR ISO-CIE 8995-1:2013 - Iluminação } \\
\text { de ambientes de trabalho - Parte 1: Interior }\end{array}$ & ILUMINAÇÃO & Nível Inferior: 5 lux \\
\hline $\begin{array}{l}\text { (COSTA, 2013) - RECOMENDAÇÕES PARA } \\
\text { ILUMINAÇÃO DE ESPETÁCULOS }\end{array}$ & ILUMINAÇÃO & Nível Aceitável: 50 lux \\
\hline $\begin{array}{llr}\text { (GRIGOLETTI, 2007) - } & \text { RECOMENDAÇÕES } \\
\text { PARA PROJETO DE ILUMINAÇÃO: AMBIENTES } \\
\text { INTERNOS (ATIVIDADES CULTURAIS E } \\
\text { ARTÍSTICAS) }\end{array}$ & ILUMINAÇÃO & $\begin{array}{l}\text { Contrastes: Baixo (3:1); } \\
\text { Médio (10:1); Alto (20:1); } \\
\text { Máximo (40:1); Zonas de } \\
\text { Transição (>20:1) }\end{array}$ \\
\hline NBR 15575:2013 & ACÚSTICA & $N A^{*}$ \\
\hline $\begin{array}{l}\text { ABNT NBR 10151:2000 Versão Corrigida:2003 } \\
\text { - Acústica - Avaliação do ruído em áreas } \\
\text { habitadas, visando o conforto da } \\
\text { comunidade - Procedimento }\end{array}$ & ACÚSTICA & $\mathrm{NA}^{*}$ \\
\hline $\begin{array}{l}\text { ABNT NBR 10152:2017 - Acústica - Níveis de } \\
\text { pressão sonora em ambientes internos a } \\
\text { edificações }\end{array}$ & ACÚSTICA & $\mathrm{NA}^{*}$ \\
\hline NR 15 & ACÚSTICA & Limite: $85 \mathrm{~dB}(\mathrm{~A})$ \\
\hline $\begin{array}{l}\text { (BISTAFA, 2011) - PROJETO DE ACÚSTICA } \\
\text { PARA AMBIENTES INTERNOS }\end{array}$ & ACÚSTICA & Aceitável: $65 \mathrm{~dB}(\mathrm{~A})$ \\
\hline
\end{tabular}

Fonte: Adaptado de (CACCIATORI, et al., 2018)

\section{Quadro 3 - Diagnósticos: Conforto Lumínico - Descrição Completa, Resumida e Recomendações Aplicáveis}

\begin{tabular}{|c|c|c|}
\hline $\begin{array}{l}\text { Descrição do Diagnóstico Físico: Por } \\
\text { Elemento Construtivo / Sistema }\end{array}$ & $\begin{array}{l}\text { Resumo do } \\
\text { Diagnóstico }\end{array}$ & $\begin{array}{l}\text { Recomendações } \\
\text { Aplicáveis }\end{array}$ \\
\hline $\begin{array}{l}\text { Sistema de iluminação não fornece níveis } \\
\text { suficientes de iluminância para garantir } \\
\text { níveis de segurança }\end{array}$ & $\begin{array}{l}\text { lluminação não } \\
\text { garante níveis mínimos } \\
\text { de segurança }\end{array}$ & $\begin{array}{l}\text { Adequação de níveis de } \\
\text { iluminância } \\
\text { atendimento da IT-18 }\end{array}$ \\
\hline $\begin{array}{l}\text { Nível de iluminância atende aos níveis de } \\
\text { segurança }\end{array}$ & $\begin{array}{l}\text { Nível de iluminação } \\
\text { atende aos níveis de } \\
\text { segurança }\end{array}$ & $\begin{array}{l}\text { Estudos para melhorar } \\
\text { condições de conforto }\end{array}$ \\
\hline $\begin{array}{l}\text { Nível de iluminação atende } 50 \text { lux (nível } \\
\text { aceitável) e alguns ambientes preferidos } \\
\text { atendem a este critério integral ou } \\
\text { parcialmente }\end{array}$ & $\begin{array}{l}\text { Nível de iluminância } \\
\text { atende nível aceitável } \\
\text { de } 50 \text { lux }\end{array}$ & $\begin{array}{l}\text { APO Permanente } \\
\text { lluminação }\end{array}$ \\
\hline $\begin{array}{l}\text { Contrastes de luminâncias superior ao } \\
\text { máximo recomendado (40:1), possibilidade } \\
\text { de desconforto visual e/ou falta de } \\
\text { segurança na circulação }\end{array}$ & $\begin{array}{ll}\text { Proporção } & \text { de } \\
\text { contraste superior ao } \\
\text { máximo }\end{array}$ & $\begin{array}{l}\text { Adequação } \\
\text { proporções } \\
\text { contrastes }\end{array}$ \\
\hline $\begin{array}{l}\text { Contrastes de luminâncias dentro dos } \\
\text { limites [níveis médios (10:1) e alto (20:1)], } \\
\text { despertar da percepção visual }\end{array}$ & $\begin{array}{l}\text { Proporção de } \\
\text { contraste dentro dos } \\
\text { limites recomendados }\end{array}$ & $\begin{array}{l}\text { APO Permanente } \\
\text { lluminação }\end{array}$ \\
\hline $\begin{array}{l}\text { Proporção de contraste dentro dos limites } \\
\text { recomendados }\end{array}$ & $\begin{array}{l}\text { Proporção de } \\
\text { contraste dentro dos } \\
\text { limites recomendados }\end{array}$ & $\begin{array}{l}\text { APO Permanente } \\
\text { lluminação }\end{array}$ \\
\hline $\begin{array}{l}\text { Decorrente da baixa iluminância destes } \\
\text { ambientes, as superfícies não refletem, } \\
\text { impossibilitando a medição de luminâncias } \\
\text { e devido a esta situação, as medições não } \\
\text { foram realizadas nestes ambientes }\end{array}$ & $\begin{array}{l}\text { Impossibilidade de } \\
\text { realizar a medição - } \\
\text { baixa iluminância }\end{array}$ & $\begin{array}{l}\text { APO Permanente } \\
\text { lluminação }\end{array}$ \\
\hline
\end{tabular}


Impossibilidade de realizar medição devido ao ofuscamento da iluminação natural
Impossibilidade de APO Permanente

realizar medição - lluminação

ofuscamento

iluminação natural

Fonte: Adaptado de (CACCIATORI, et al., 2018)

Foram realizados 36 diagnósticos e 24 recomendações conforme Número de Diagnósticos e Recomendações por Tema-Quadro 4.

Quadro 4 - Número de Diagnósticos e Recomendações por Tema

\begin{tabular}{|c|c|c|}
\hline Tema & $\begin{array}{c}\text { Número de } \\
\text { Diagnósticos }\end{array}$ & $\begin{array}{c}\text { Número de } \\
\text { Recomendações }\end{array}$ \\
\hline Conforto Térmico & 5 & 2 \\
\hline Conforto Acústico & 2 & 4 \\
\hline Conforto Lumínico - Iluminância & 3 & 3 \\
\hline Conforto Lumínico -Luminância & 5 & 1 \\
\hline Acessibilidade & 6 & 4 \\
\hline Segurança Contra Incêndio & 10 & 5 \\
\hline Segurança Durante o Uso & 5 & 5 \\
\hline
\end{tabular}

Fonte: Elaborado pelas autoras (2019).

Destaca-se também a percepção e a satisfação dos usuários em relação aos temas - Gráfico 1.

\section{Gráfico 1 - Comparação entre percentual de notas por tema entre Visitantes e Funcionários}

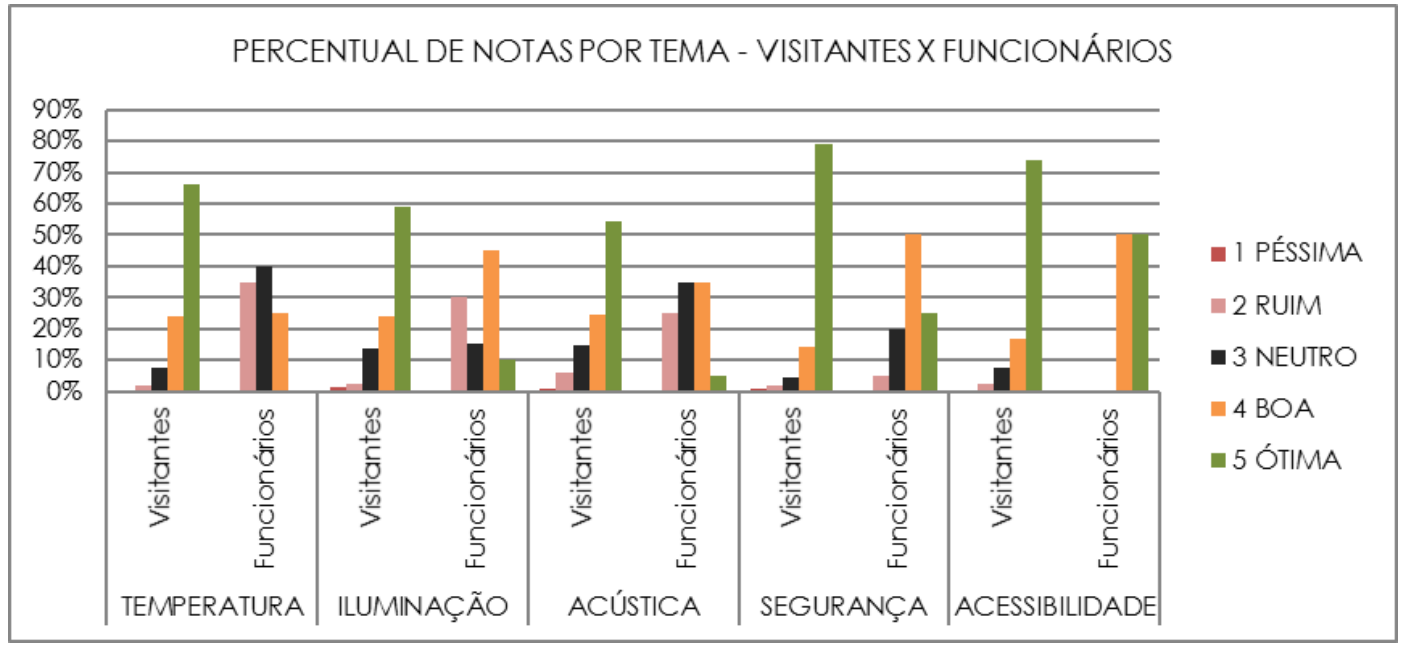

Fonte: Elaborado pelas autoras (2019) baseado em (CACCIATORI, et al., 2018)

Funcionários possuem mais avaliações negativas em relação aos visitantes, atribuídas às variações de tempo de permanência no local e frequência. $O$ visitante permanece em média 5 minutos em cada ponto do percurso da exposição enquanto o funcionário permanece períodos de no mínimol:30h em cada ponto, em uma jornada diária de trabalho, com ou sem mobilidade entre pontos / ambientes.

Este dado nos faz retornar à pergunta inicial: Para quem se projeta um museu interativo? Muitas recomendações para o caso do Museu do Futebol, foram voltadas para o atendimento dos usuários permanentes - os funcionários. No entanto, o desafio de equilibrar e garantir a liberdade criativa para um projeto de exposição interativa e o atendimento simultâneo de demandas normativas, legais e dos diferentes perfis de usuário, torna necessário que tal pergunta seja feita várias vezes ao longo do projeto, para cada decisão a ser tomada. 


\section{CONSIDERAÇÕES FINAIS}

Verificou-se que nem sempre estão disponíveis critérios normativos diretamente aplicáveis ao contexto de uma exposição interativa. No caso de um estudo de adequação em termos de conforto ambiental, por exemplo, as propostas devem ser direcionadas ao contexto e características próprias do partido que se toma, que por vezes podem ser exclusivas de um museu em específico.

Por outro lado, as decisões sobre a iluminação devem ser associadas a aspectos de segurança, resultando em recomendações objetivas, com tratamento técnico e normativo, independentemente da percepção e do nível de satisfação dos usuários, que em geral foi elevado neste estudo de caso.

A avaliação do nível de satisfação de usuários evidenciou que a percepção das pessoas é alterada com o tempo de permanência e tipo de interação com o ambiente construído. O nível de satisfação dos funcionários é menor do que dos visitantes. Esta verificação reforça a recomendação de implantação de um processo de APO permanente, para refinamento das informações e recomendações.

Para o projeto e operação de museus interativos, permanece o desafio de integrar:

- O atendimento equilibrado das expectativas de funcionários e visitantes;

- A promoção de experiências que ampliem a difusão da arte e da cultura para a sociedade;

- A garantia da segurança - aspecto sobre o qual a operação não deve se omitir desde as primeiras decisões de projeto;

- A viabilidade operacional - instituições que dependem de verbas públicas, a limitação destas pode se tornar uma forte restrição à sistemas operacionais complexos, normalmente resultantes de projetos que priorizam a experiência do visitante.

O atendimento simultâneo destes objetivos se torna cada vez mais viável, a partir dos dados conhecidos, das novas tecnologias e métodos de projeto e da condução de projetos por profissionais com perfil integrador.

\section{AGRADECIMENTOS}

À equipe do Museu do Futebol e ao Conselho Nacional de Desenvolvimento Científico e Tecnológico pela bolsa produtividade concedida a Sheila Walbe Ornstein.

\section{REFERÊNCIAS}

ASSOCIAÇÃO BRASILEIRA DE NORMAS TÉCNICAS (ABNT). ABNT NBR 14718: 2008 - Guarda-corpos para edificação. Rio de Janeiro: ABNT, 2008.

THE AMERICAN INSTITUTE OF ARCHITETCTS (AIA). Integrated Project Delivery: A Guide, Versão 1, 2007.

ALHARBI, M.; EMMITT, S.; DEMIAN, P. Transferring architectural management into practice: a taxonomy framework. Frontiers of Architectural Research, 2015. p. 237-247. Disponivel em: <https://doi.org/10.1016/j.foar.2015.04.001>. 
ANDERY, P. R. P.; VEIGA, A. C. R. Considerações sobre o gerenciamento de projetos complexos: o caso de exposições museográficas. Construindo, Belo Horizonte, v. 5, n. 2, jul./dez. 2013.

ARAUJO, A. P. et al. Ensaio metodológico sobre a utilização de transectos móveis no período diurno em Presidente Prudente. REVISTA FORMAÇÃO, [S.I.], v. 1, n. 17, p. 77-95, 2010. Disponivel em:

<http://revista.fct.unesp.br/index.php/formacao/article/download/415/453>. Acesso em: 01 jun. 2018.

BISTAFA, S. R. ACÚSTICA APLICADA AO CONTROLE DO RUÍDO. 2. ed. São Paulo: Blucher, 2011.

BORDASS, B.; LEAMAN, A. Phase 5: Occupancy - post-occupancy evaluation. In: PREISER, W. F. E.; VISCHER, J. C. (. ). Assessing Building Performance. 1. ed. Oxford: Elsevier, 2005. Cap. Part Two - 7, p. 72-78.

COSTA, G. J. C. lluminação Econômica: Cálculo e Avaliação. 4ª . ed. Porto Alegre: EdiPUCRS, 2013

CACCIATORI, M. M. F. et al. Relatório de Avaliação Pós-Ocupação (APO) do Ambiente Construído do Museu do Futebol. 2018, 207 p. Programa de PósGraduação da Faculdade de Arquitetura e Urbanismo, Universidade de São Paulo, Disciplina Avaliação Pós-Ocupação do Ambiente Construído , São Paulo, 2018.

GONÇALVES, W. D. B. Interfaces e conflitos entre o conforto ambiental humano e a conservação preventva do acervo em edifícios que abrigam coleções.

Museologia e Patrimônio, v. 9, n. 2, p. 10-17, junho 2016. Disponivel em: $<$ file://C:/DOWNLOAD\%20GOOGLE\%20CHROME/481-2354-1-

PB\%20(1).pdf>.Acesso em: 25 mai.18.

GRIGOLETTI, G. C. . B. D. . P. G. S. Caderno didático - DAU2062 - Conforto Ambiental II. Universidade Federal de Santa Maria. Santa Maria, p. 71. 2007.

INSTITUTO NACIONAL DE METEOROLOGIA (INMET). Consulta Dados da Estação Automática: São Paulo (Mirante de Santana) (SP) no Site do INMET., São Paulo, 2018. Disponivel em:

<http://www.inmet.gov.br/sim/sonabra/dspDadosCodigo.php?ODM3ODE>. Acesso em: 27 mai. 2018.

INTERNATIONAL WELL BUILDING INSTITUTE (IWBL). Consulta ao The Well Building Standard. [S.I.]: [s.n.], 2018. Disponivel em: <http://standard.wellcertified.com/>. Acesso em: 03.05.2018.

ORNSTEIN, S. W.; ANDRADE, C. M. D.; LEITE, B. C. C. 12. Assessing Brazilian workplace performance. In: PREISER, W. F. E.; VISCHER, J. C. (. ). Assessing Building Performance. 1. ed. Oxford: Elsevier, 2005. Cap. Part Three - Case Studies, p. 128-138.

OXMAN, R. Theory and design in the first digital age. Design Studies, v. 27, n. 3 , 2006. p. 229-265.

PUGLIESI, N. Arquitetura interativa dá nova função aos projetos: a de se comunicar. Portal AECweb, 2018. Disponivel em:

<https://www.aecweb.com.br/cont/m/rev/arquitetura-interativa-da-novafuncao-aos-projetos-a-de-se-comunicar_10939_10_0>. Acesso em: 09 fev. 2019.

SUCCAR, B. Building information modelling framework: A research and delivery foundation for. Automation in Construction, 2009. p. 357-375. 
VEIGA, A. C. N. R.; ANDERY, P. R. P. Gestão do processo de design de arquitetura efêmera em museus. Ambiente Construído, Porto Alegre, v.14, n.4, p. 201-215, out./dez. 2014. 